\title{
Redistribution and Growth for Poverty Reduction
}

\author{
Hulya Dagdeviren (University of Hertfordshire) \\ Rolph van der Hoeven (ILO) \\ John Weeks (SOAS)
}

Note:

1) This paper was published in revised form in Development and Change (2002), Volume 33, Issue 3.

2) Research for this paper was jointly done at ILO and SOAS. Research for this paper was funded by the International Labour Organisation. 


\title{
Redistribution Matters: Growth for Poverty Reduction ${ }^{1}$
}

\begin{abstract}
In the late 1990s the bilateral and multilateral development agencies placed increasing emphasis on poverty reduction in developing countries. This emphasis led to the establishment by the United Nations of the so-called International Development Targets for poverty reduction. The achievement of a target requires policies, and policies are most effective within an overall, coherent strategy. A poverty target might be achieved through faster economic growth alone, redistribution, or a combination of the two. This paper presents an analytical framework to assess the effectiveness of growth and redistribution for poverty reduction. It concludes that redistribution, either of current income or the growth increment of income, is more effective in reducing poverty for a majority of countries than growth alone.
\end{abstract}

\section{Introduction}

Of the many issues central to the development process, few have been characterised by the shifts, reversals and re-affirmations that have pledged the analysis of the interaction of growth, poverty and inequality. The mainstream literature has not so much evolved as fluctuated over the past fifty years. ${ }^{2}$

From the 1950s into the 1970s emphasis was on probable tradeoffs between growth and income distribution. In contrast, work in the 1970 s sought to identify redistributive mechanisms for poverty reduction without hampering growth. ${ }^{3}$ This was a short-lived focus of the literature, reversed with the rise of neo-liberalism and the Washington Consensus in the early 1980s. For the latter, growth itself would be the vehicle for poverty reduction, achieved through 'trickle-down' mechanisms not always

\footnotetext{
${ }^{1}$ An earlier version of this paper was presented to the WIDER conference on growth and poverty, May 2001.

${ }^{2}$ See Kanbur (1998) for a thorough review. Dagdeviren, van der Hoeven and Weeks (2000) also provide review of the literature on growth, poverty and redistribution.

${ }^{3}$ See Chenery, Ahluwalia, et al. (1974).
} 
clearly specified. In the last decade, both the neo-liberal analysis and the earlier view of a trade-off between growth and equity were challenged by a number of studies. ${ }^{4}$

In the late 1990s the bilateral and multilateral development agencies placed increasing emphasis on poverty reduction in developing countries. ${ }^{5}$ This emphasis led to the establishment by the United Nations of the so-called International Development Targets for poverty reduction. The achievement of a target requires policies, and policies are most effective within an overall, coherent strategy. By definition a poverty target might be achieved through economic growth alone, redistribution, or a combination of the two.

Setting a specific level of poverty to achieve by a specific date makes comparison of redistribution and growth analytically interesting. The International Development Target for 'head count' poverty, which we use, was quite specific:

The International Development Target for well-being [of US one dollar per day per head] is a practical measure of absolute poverty. It is based on an average of national poverty lines in poor countries, which reflect people's ability to afford a diet sufficient to meet minimum nutritional requirements...It thus represents an internationally agreed operational method of identifying the number of people who by any standard have unacceptably low incomes. $\cdots$

The...target is to reduce by half the proportion of people in developing countries living in extreme poverty by 2015 . The base year is $1990 \ldots$ (DFID 2000, p. 11)

Though the target of fifty percent reduction might be narrowly interpreted as referring to the developing world as a whole, donor documents treat it as applicable to the regional and country levels. It may be that for some countries there is no feasible growth

\footnotetext{
${ }^{4}$ See, Aghion (1999), Alesina (1994), van der Hoeven (2000)

${ }^{5}$ The International Development Targets, set by the Social Summit in 1996, are presented and discussed in Hanmer and Nascold (2000). The UK Department of International Development officially adopted these targets (DFID 2000, and Goudie \& Ladd 1999). More modest targets were set by USAID (USAID 2001). The new emphasis of the international financial institutions on poverty is reflected in the inclusion of poverty strategies in loan agreements (see IMF \& World Bank 1999). For a sceptical view, see Cramer (2000).
} 
rate, given historical performance, and changes in inequality and resource availabilities that would achieve it. The World Bank warned that such might be the case:

Progress in reducing extreme poverty during the 1990s was constrained by increasing inequality in a few countries that accounted for a large share of the world's poor. In looking ahead to 2015, continued increases in inequality coupled with less than robust growth would imply failure to reach the poverty target for developing countries as a group, and in particular substantial increases in the number of poor in Sub-Saharan Africa. (World Bank 2001b, p. 7)

The World Bank went on to conclude that 'the alternative [growth] scenarios highlight the importance of achieving fast growth, as well as distributing the benefits of growth equitably' (World Bank 2001b, p. 10). ${ }^{7}$ The same point is made by UK DFID, 'without growth the poverty reduction target will not be achieved, but it is not enough on its own' (DFID 2000, p. 11). ${ }^{8}$

Despite the wide-spread recognition that GDP growth should be combined with mechanisms of redistribution to achieve the international poverty target, one finds little quantitative evaluation of the relative impact of the two poverty determining mechanisms, either in the abstract or for specific countries; i.e. what would be the reduction in poverty for a given rate of growth and a given redistribution? Were this question answered, one could then assess the growth and redistribution mechanisms in light of the resource cost of their poverty reducing impact.

To calculate the poverty-reducing impact of growth and redistribution, we use a simple analytical framework that formulates two abstract possibilities: poverty reduction through distribution-neutral growth (DNG) and poverty reduction through a redistribution of each period's growth increment (redistribution with growth, RWG). These are compared to a conventional one-off redistribution of current income (RCY). Without a dated poverty target, the question we address, which is more effective for poverty reduction, growth or redistribution, would be analytically trivial. If a country's per capita

\footnotetext{
${ }^{6}$ This document was taken off the internet, without pagination. Page numbers given here are based on numbering form the first pages of text ('Introduction').

${ }^{7}$ Evidence that the pattern of growth in both developed and developing countries became more unequal is presented in Cornia (1999).

${ }^{8}$ For further discussion of the achievability of the targets see Demery \& Walton (1998) and
} 
income lies above the designated poverty line and one ignores the practicalities of redistribution, poverty can be eliminated by a one-off redistribution in any current time period, while per capita growth would take several or many periods to achieve the same result. The imposition of a specific target on the poverty agenda makes our calculations policy-relevant.

We can note that there is a further possibility, growth with a worsening distribution of income. This outcome characterised many if not most of the countries in transition from central planning to market regulation during the 1990s (and China perhaps as early as the 1980s). Clearly, such a growth pattern would reduce the poverty reducing potential of growth. In effect, it represents a dynamic transfer from the poor to the non-poor. In what follows we note but do not quantify this scenario. This is because, first, its consequence for poverty is clear. Second, we address ourselves to policy outcomes whose purpose is to reduce poverty in order to meet the International Development Targets. For all of the countries covered by our empirical calculations, preventing a worsening distribution of income is a precondition to meet these targets.

\section{Analytical and Policy Framework}

The evaluation of the effectiveness of growth and distribution for poverty reduction would be required even were it the case that for the vast majority of countries historical growth rates would achieve the poverty target (see van der Hoeven 2000). Any target growth rate, in this case for poverty reduction, has an opportunity cost in foregone consumption compared to lower rates. This real resource cost can be compared to the cost of achieving the same poverty reduction at a lower growth rate. Economic growth is a means, and raising the rate of economic growth without considering the opportunity cost would be the domestic equivalent of mercantilism.

The relevance of the opportunity cost of raising growth rates passes from academic to practical interest because, for the vast majority of countries, maintaining

Hanmer \& Nascold ( 2000). 
historical growth rates would not be sufficient to meet the international poverty target. ${ }^{9}$ Table 1, taken from Hanmer and Nascold (2000), demonstrates the inadequacy of past growth performances for the major developing regions. Only for the East Asia and Pacific countries was growth above the rate necessary to reach the poverty target. For the sub-Saharan region, the Middle East and North Africa, and Latin America, both long-run rates (1965-97) and growth in the 1990s were below what would be required to reach the poverty target with distribution-neutral growth. In the case of South Asia, a relatively modest increase on the performance of the 1990s in per capita growth, of about twenty percent, would be sufficient. Performance for the Central and Eastern European countries and central Asian countries would be more difficult to assess. The pre-1990 rates were sufficient, but the post-reform performance far below target. It is probably the case that some of the Central and Eastern European countries would achieve the growth target, while the central Asian countries could not.

For all the regions the opportunity cost of the target growth rates appears relevant in light of the substantial degree of income inequality (last column of the table). To consider this further, an analytical framework is required in which 'growth' and 'redistribution' are specified rigorously. Using the absolute, internationally comparable poverty line discussed above, we employ a simple model to generate our empirical calculations. We define the income distribution of a country over the adult population, which we divide into percentiles $\left(\mathrm{h}_{\mathrm{i}}\right)$, and the mean income of each percentile is $\mathrm{Y}_{\mathrm{i}}$. The distribution of current income conforms to the following two parameter function:

$$
\mathrm{Y}_{\mathrm{i}}=\mathrm{Ah}_{\mathrm{i}}{ }^{\alpha}
$$

While this function will tend to be inaccurate at the ends of the distribution, its simplicity allows for a straight-forward demonstration of the interaction between distribution and growth. Each country's distribution differs by the degree of inequality (the parameter ) and the scalar A, which is determined by overall per capita income. Thus,

$$
\mathrm{A}=\beta \mathrm{Y}_{\mathrm{pc}}
$$

and

\footnotetext{
${ }^{9}$ A discussion of this issue is found in Demery \& Walton (1998).
} 
$Y_{i}=\beta Y_{p c} h_{i}^{\alpha}$

Total income is, by definition,

$\mathrm{Z}=\mathrm{m} \sum \beta \mathrm{Y}_{\mathrm{pc}} \mathrm{h}_{\mathrm{i}}^{\alpha}$. for $1=1,2 \ldots 100$ and $\mathrm{m}$ is the number of people in each percentile.

If the poverty line is $\mathrm{Y}_{\mathrm{p}}=\mathrm{P}$, we can solve for the percentile in which it falls, which is also the percentage in poverty $(\mathrm{N}){ }^{10}$

$$
\mathrm{h}_{\mathrm{p}}=\mathrm{N}=\left[\mathrm{P} / \beta \mathrm{Y}_{\mathrm{pc}}\right]^{(1 / \alpha)}
$$

If we differentiate $\mathrm{N}$ with respect to per capita income, we can express the proportional change in the percentage of the population in poverty in terms of the growth rate of GDP and the distributional parameters:

$$
\mathrm{DN} / \mathrm{N}=n=-y[1 / \alpha][\mathrm{P} / \beta]^{(1 / \alpha)}
$$

Equation 5 can be used to generate a family of iso-poverty curves, of decreasing level as they shift to the right, shown in Figure 1, on the assumption that $\alpha$ is constant. The diagram clarifies the policy alternatives: redistribution of current income (RCY) involves a vertical (downward) movement, distribution neutral growth (DNG) a horizontal (rightward) shift, and RWG is represented by a vector lying between the two. The diagram also shows the case of increasing inequality growth (IIG), in which the growth of per capita income so worsens the distribution of income that it leaves poverty unchanged (movement along the constant poverty level curve for $\mathrm{P}=20$ percent). Perhaps too optimistically, we do not treat this as a planned outcome, since we address policies to reduce poverty.

The diagram implies generalisations that will be demonstrated by the empiricallybased calculations in the next section. First, because the schedules converge to the left, the impact of redistribution on poverty declines as per capita income declines. At low incomes, both redistribution and redistribution with growth are less effective, relatively to distribution neutral growth. Second, for a given per capita income, the lower the level of inequality, the greater is the impact of redistribution on poverty reduction. In other

${ }^{10}$ A characteristic of this distribution function is that the two parameters, $\alpha$ and $\beta$, are not independent of each other. This characteristic does not affect our calculations in the next section, because we use the function only for the initial period's income. 
words, when the poor are clustered close to the poverty line, the income transfer necessary to raise them out of poverty is less than if the same number of households were unequally distributed.

The growth-distribution interaction on poverty reduction can also be shown for growth rates, using equation 6. In Figure 2, the percentage reduction in poverty is on the vertical axis and growth rates on the horizontal. Three lines are shown, for increasing degrees of inequality as they rotate clockwise (increasing values of $\alpha$ holding initial per capita income constant). The figure shows that for any initial per capita income, growth reduces poverty more, the less the inequality of initial income distribution. From the initial position at point a, distribution neutral growth increases the rate of poverty reduction along the schedule $\alpha=1.3$ to point $\mathrm{b}$ (an increase in the growth rate with distribution unchanged), redistribution of current income involves a vertical movement to point $\mathrm{c}$, and a shift from a to $\mathrm{d}$ is a case of redistribution with growth.

In anticipation of our empirical calculations, that will show redistribution to be more effective in reducing poverty than growth for a majority of countries (but not all), note that using a head count measure of absolute poverty has an inherent bias towards the effectiveness of growth alone (DNG). Assuming all income distributions to be relatively continuous, ${ }^{11}$ any distribution neutral growth in per capita income, no matter how low, will reduce poverty. However, redistribution reduces poverty only to the extent that it moves a person above a per capita income of US\$ 365. To put the point another way, redistributions that reduce the degree of income poverty for those below the absolute poverty standard do not qualify as poverty reducing. ${ }^{12}$ Even confronted with this strong condition, we show that simple redistribution rules result in powerful outcomes for poverty reduction. The redistribution we propose, in the Chenery, et. al. (1974) tradition, ${ }^{13}$ is equal absolute increments across all percentiles, top to bottom. This could be viewed as relatively minimalist, with alternative redistribution rules considerably more

\footnotetext{
${ }^{11}$ That is, we assume there are no 'gaps' in the distribution below and near the poverty line.

${ }^{12}$ A redistribution of one percentage point of GDP from the richest ten percent of the population to the poorest ten percent, equally distributed among the latter, would improve raise the incomes of all those in the lowest decile, but might shift none of them above the poverty line.

${ }^{13}$ This volume was path breaking, in that it focused World Bank policy on strategies of poverty reduction. Particularly important were two papers by Ahluwalia (1974a and 1974b), and by Ahluwalia and Chenery (1974a and 1974b). A good review of the distribution literature of the
} 
progressive. This, a special case of the redistribution with growth strategy, we call equal distribution growth (EDG).

Assuming that the absence of a distribution policy implies distribution neutral growth, the proposed equal distribution growth implies income transfers, or an implicit policy-generated tax. Let aggregate income in the base period be $Z_{0}$ and in the next period $Z_{1}$, and assume the latter is unchanged by how $\left(Z_{1}-Z_{0}\right)$ is distributed across percentiles. ${ }^{14}$ With distribution neutral growth the income in each percentile $\left(\mathrm{Y}_{\mathrm{i}}\right)$ increases by $\left(\mathrm{Y}_{0 \mathrm{i}}\left[1+y^{*}\right]\right)$, where $y^{*}$ is the rate of per capita income growth (by definitional the same across the distribution). Under equal distribution growth, each percentile receives an income increment of $\left(Z_{1}-Z_{0}\right) / 100$. This post-transfer or secondary distribution of income by percentile is noted as $\mathrm{Y}_{1 \mathrm{i}}{ }^{\mathrm{e}}$, for period 1 . Using the redistribution rule and our symbols,

$$
\begin{aligned}
& \mathrm{Z}_{1}=\left(1+y^{*}\right) \mathrm{Z}_{0}=\left[\Sigma \mathrm{Y}_{1 \mathrm{i}}\right] \text {, by definition, and } \\
& \mathrm{Y}_{1 \mathrm{i}} \mathrm{e}=\mathrm{Y}_{0 \mathrm{i}}+\left\{\left[\left(y^{*}\right) \mathrm{Z}_{0}\right] / 100\right\}=\mathrm{Y}_{0 \mathrm{i}}+\mathrm{E}_{1} \\
& \text { Where } \Sigma\left[\mathrm{Y}_{1 \mathrm{i}}\right]=\Sigma\left[\mathrm{Y}_{1 \mathrm{i}}{ }^{\mathrm{e}}\right] \text {, by definition. }
\end{aligned}
$$

Defining $\mathrm{T}_{\mathrm{i}}$ as the implicit redistribution tax for each percentile,

$$
\mathrm{T}_{\mathrm{i}}=\left(\mathrm{Y}_{1 \mathrm{i}}-\mathrm{Y}_{1 \mathrm{i}}^{\mathrm{e}}\right) /\left(\mathrm{Y}_{1 \mathrm{i}}-\mathrm{Y}_{0 \mathrm{i}}\right)
$$

The redistribution tax is negative up to the point of mean income (positive income transfer), then positive above (negative income transfer). If income were normally distributed, the tax would be negative through the fiftieth percentile. It is obvious that the more skewed the distribution, the higher is the percentile associated with average per capita income (the fiftieth percentile being the lower bound). Calculated by percentiles, we find that the redistribution tax is not out of line with rates that have applied in many developed countries. For example, the extremely unequal Brazilian distribution for the 1990s, with a Gini coefficient of $60,{ }^{15}$ implies a marginal tax rate on the hundredth

1960s and 1970s is found in Fields (1980).

${ }^{14}$ This assumption is discussed in the section on policy.

${ }^{15}$ In this paper Gini coefficients will be reported on a scale of zero to one hundred. 
percentile of slightly more than eighty percent, well below the maximum for such rates in the United States and Western Europe after World War II into the 1960s. Further, if the redistribution is affected through growth policies rather than direct transfers, the so-call redistribution tax is implicit rather than levied.

The proposed marginal redistribution has characteristics that derive automatically from the nature of income distributions. First, and most obvious, the relative benefits of the equal absolute additions to each income percentile increase as one moves down the income distribution. Second, and as a result of the first, for any per capita income, the lower the poverty line, the greater will be the poverty reduction. As a corollary, when a policy distinction is made between degrees of poverty, with different poverty lines, the marginal redistribution will reduce 'severe' poverty more than it reduces less 'severe' poverty. Third, the more unequal the distribution of income below the poverty line, the less is the reduction in poverty for any increase in per capita income, or redistribution of that increase.

Before moving to our empirical investigation of alternative growth paths, it is appropriate briefly to comment on our 'benchmark' path, distribution neutral growth. Dollar and Kray (2000) reach the conclusion, based on cross-country regressions, that the typical outcome of the growth process in developing countries is to leave the income share of the lowest quintile unchanged; ie., distribution neutral growth (see also Ravallion 2001). The authors characterise this with the phrase, 'growth is good for the poor' (italics in the original). ${ }^{16}$ This statement has limited analytical content, for if the elasticity of the income share of the poor with respect to growth is positive, 'growth is good for the poor' by definition. Why an elasticity of unity should be the borderline between growth being 'good' or 'bad' for the poor is not clear; indeed, it would seem arbitrary. The policy issue is not whether growth is or is not good for the poor (it is except in a few circumstances), but what policy measures can make it better for the poor. ${ }^{17}$

\footnotetext{
${ }^{16}$ The same point, that distribution neutral growth appears to be the norm, is demonstrated empirically in a much simpler way and with less fan-fare in Ferreira (1999).
} 


\section{Redistribution with Growth: Empirical Calculations}

In this section we inspect the impact on poverty in fifty countries of three calculation exercises, corresponding to different distributional outcomes: 1) a one percent distribution neutral increase in per capita GDP; 2) a one percent increase in per capita GDP, distributed equally across income percentiles; and 3) a one percent redistribution of income from the richest twenty percent to the poorest twenty percent. The effectiveness of the outcomes in reducing poverty is judged by the time period required to reduce poverty by a given percentage. This corresponds to the goal of the International Poverty Targets. In all calculations the US one dollar a day 'head count' measure of poverty is used.

Before proceeding to the calculations, a warning is required about the use of the head country poverty measure, and of the relationship between per capita income and the poverty line. Because we measure per capita income in constant US dollars and compare this statistic across countries, there is an assumption of purchasing power parity; i.e., that one-dollar per day measures the same standard of living in all the sample countries. Even were it the case that income per capita in each country were normalised for purchasing power parity, it would not follow that the poverty bench mark, US\$365, was equivalent. This would follow if and only if the vector of purchasing power equivalent prices was the same across the entire distribution. Since the poor often pay different prices than the non-poor, and expenditure weights will vary across the distribution, the adjustment appropriate to per capita income would not necessarily apply at and below the poverty line.

Second, as explained below, we estimate the poverty line on the basis of a distribution function and GDP per capita. In place of the latter one should use personal income (factor incomes plus transfer payments). However, for most of the countries in the sample, personal income statistics are not available. These two problems, the problems with purchasing power parity across the distribution and use of GDP rather than personal income, affect the precision of our calculations, but not the general principle we seek to demonstrate. The two problems imply that our calculations underestimate the

\footnotetext{
${ }^{17}$ The Dollar and Kraay paper is considered in detail in Lübker, Smith and Weeks (2002).
} 
poverty share in the sample countries. However, once per capita income figures are chosen for countries and it is assumed that purchasing power parity prices are the same across the distribution, our conclusions about policy alternatives follow. We could, for example, eliminate both problems by carrying out our exercise on a hypothetical number set composed of purchasing power parity personal incomes. However, we chose base our calculations on real countries and the best available measures of per capita income and distribution. We judge the loss of precision to be outweighed by the gain in policy relevance.

The necessary condition for a country to be included in the calculations is that there were statistics on the income share for quintiles, ${ }^{18}$ and that the country was included in the World Bank's estimates of absolute poverty. The World Bank estimates were generated by converting each country's per capita income to constant US dollars for a base year, then setting a poverty line of US one dollar a day. ${ }^{19}$ The specified poverty percentile for one dollar a day is implied by the assumptions made about the distribution of income within each quintile.

To estimate the impact of a change in income on the percentage of households in poverty, it is necessary to make explicit the implicit intra-quintile distribution of income. It was not necessary to know the distribution within all quintiles, but only for the quintile in which the poverty line fell, before and after the three calculations. Our model implies the method of estimating the intra-quintile distribution (equation 5). To make the model more closely conform to each country's distribution, we let the parameter $\alpha$ vary by quintile: $\alpha_{1}$ applies from the first quintile to the percentile that contains the mean income of the second quintile, $\alpha_{2}$ applies from that point to the mean income of the third quintile, $\alpha_{3}$ to the mean of the fourth quintile, and $\alpha_{4}$ for the rest of the distribution. Except for very low income countries, the poverty line will fall into the first or second quintile, so only $\alpha_{1}$ and $\alpha_{2}$ need be estimated. To estimate those we assume that in the relevant

\footnotetext{
${ }^{18}$ The major source was the WIDER income distribution database. See appendix for details by country.

19 The World Bank also provides estimates of the population below two dollars day, but this measure is not used here. The accuracy of these poverty levels is open to criticism (Karshenas 2001). For our purposes this is relatively unimportant, since the conclusions we reach are relatively insensitive to the exact level of estimated poverty in each country.
} 
quintiles mean and median income are equal. Empirical evidence indicates this to be a close approximation to actual distributions for the bottom two quintiles. ${ }^{20}$ Since we need to estimate the income distribution only in the relevant quintiles, our calculations do not use inequality measures for the distribution as a whole (e.g. Gini Coefficients). Errors in our calculations would arise from inaccuracies in the estimation of quintile income shares rather than inaccuracies in measures of overall inequality. These inaccuracies in income shares could affect our categorising of countries, but not the general argument we develop on the basis of our calculations.

A further note is necessary on the nature of the data and the consistency of the results. For some countries quintile shares were expenditure-based while for others they were income-based. However, this should not reduce the consistency of our results. Using mixed data of income-based and expenditure-based estimates can be problematic in studies that, for instance, aim to compare poverty levels across countries or in a specific country over time. ${ }^{21}$ Our objective in this paper is to assess the relative effectiveness of a number of poverty reduction strategies. Our main reference is the estimates 'effectiveness ratio' which is not sensitive to the variation in the definition of data (income versus expenditure based).

With these warnings made, we can use our assumptions to solve for the relevant quintile distribution parameters. If $\mathrm{Y}(\mathrm{q} 1 \mathrm{~m})$ and $\mathrm{Y}(\mathrm{q} 2 \mathrm{~m})$ are the mean incomes of the first and second quintiles (both known), then

$$
\begin{aligned}
& \mathrm{Y}(\mathrm{q} 1 \mathrm{~m})=\beta[10.5]^{\alpha_{1}} \\
& \mathrm{Y}(\mathrm{q} 2 \mathrm{~m})=\beta[30.5]^{\alpha_{2}}
\end{aligned}
$$

One solves for the initial poverty level as above (equation 5 ). ${ }^{22}$ After one percent distribution neutral growth in one time period, the income of that percentile rises by one percent (i.e., US $\$ 365 \times(1.01)=368.85$ ), and for equal distribution growth by the

\footnotetext{
${ }^{20} \mathrm{We}$ are indebted to Malte Lueker for demonstrating this to us, using data from several developing countries. More details can be provided on request. Our calculations are hardly affected by the degree to which the mean and medium incomes differ.

${ }^{21}$ A similar problem is observed for some of the Gini coefficients in Table 2 which seem of limited credibility; e.g. greater measured inequality for China than for India and Pakistan.

${ }^{22}$ The distribution parameters are not sensitive to the difference between mean and median income, unless the difference varies by quintile. The parameter $\alpha_{i}$ is determined by the share of income across quintiles.
} 
increment in aggregate national income equally distributed across all percentiles (see equation 7). With the income of the initial period's poverty line percentile known for the next period, one can calculate the new poverty percentile (that is, the percentile for which $\mathrm{Y}_{\mathrm{i}}=\mathrm{US} \$ 365$ in the second period).

Having explained the calculations, we turn to the empirical results. Table 2 provides the basic statistics for the calculations for the fifty countries: per capita income, the Gini coefficient, and the percentage of the population with income per head below one US dollar (the poverty line), as estimated by the World Bank. In Table 3, the calculations are reported, for the two growth exercises, distribution-neutral growth (DNG in the table) and equal distribution growth (EDG). Columns one and two give the estimates of the percentile of households lifted out of US one dollar poverty as the result of one percent growth, distribution-neutral and equal-distribution, respectively. Column three reports the 'effectiveness of redistribution' ratio. This is the ratio of poverty reduction for equal distribution growth to distribution neutral growth (column 1 divided by column 2). This ratio is greater than unity for forty-seven of the fifty countries. That is, for ninety-four percent of the countries, the equal distribution grow strategy reduces poverty more in a given time period than a distribution-neutral growth strategy. This in itself is not surprising, for distribution-neutral growth is only more effective in reducing poverty for countries with fifty percent or more of the population below the poverty line. It is striking how much more effective equally distributed growth proves to be in reducing poverty for most countries. For middle income countries the greater effectiveness of redistribution is quite clear: for a large proportion, the effectiveness ratio is in excess of three; ie., equal distribution growth raises three times as many households from poverty than distribution neutral growth over any time period.

The benefits of equal distribution growth are greater the higher is a country's per capita income, and the more equal the distribution below the poverty line. The results imply that growth with redistribution would be particularly appropriate for the Latin American countries and those of North Africa and the Middle East. Its poverty-reducing advantage would be less for the sub-Saharan countries (except South Africa), because of their low per capita incomes. Because the table includes only a few low-income 
countries, it overstates the proportion of countries for which redistribution with growth is more effective than distribution neutral growth. This over-emphasis is discussed below.

As the poverty line rises up a country's income distribution, the effectiveness of redistribution ratio becomes less and less sensitive to measures of inequality. However, it is always the case, no matter what a country's per capita income or degree of inequality (if it is not zero), that redistribution with growth is more effective than distribution neutral growth in reducing the intensity of poverty (as opposed to the head count). The relative benefit of equal distribution growth increases as one moves down the income distribution, independently of a country's per capita income or degree of inequality. ${ }^{23}$

The redistribution with growth outcome implies a tax on all households whose income is above the mean. In which percentile the mean falls depends on the skewedness of the distribution. The final two columns (4 and 5) of Table 3 report the implied tax rate for the highest percentile, and the average rate across all percentiles whose income is redistributed towards the poorer percentiles. This calculation presents the issue of the effect of the redistribution on incentives of positive and negative transfers. ${ }^{24}$ If distribution neutral growth represents the primary (pre-tax) outcome, and equaldistribution growth the secondary (post-tax) outcome, then there is a straight-forward disincentive effect for those taxed, to be weighted against the incentive effect for the beneficiaries. We make the assumption that the incentive effect of taxes is symmetrical: if positive tax rates create a disincentive to earn further income, then negative rates create an incentive to earn income and contribute to higher national growth. If the income distribution is skewed, then the number of households enjoying an incentive to increase earnings will out-number those suffering a disincentive, and the impact on growth should be positive. Whether this increases or decreases the growth rate would depend on the income-weighted average of the incentive effects.

These growth calculations can be compared to the more conventional exercise, a direct redistribution from the rich to the poor. This is calculated in Table 4, where it is

\footnotetext{
${ }^{23}$ However, in the 1990s inequality increased dramatically in most of these countries (Brundenius and Weeks 2001), marking them more like the Latin American group for purposes of poverty reduction analysis.

${ }^{24}$ The rates are marginal, not average, applying to the increase or growth increment in per capita income.
} 
assumed that one percentage point of total national income is shifted from the top quintile to the poor, and distributed equally among those households. ${ }^{25}$ This assumption is equivalent to assuming that a one percent increase in GDP goes to those below the poverty line. For each country the reduction in the poverty measure for the one percent redistribution appears in column two, and can be compared to column three in Table 2, where poverty prior to redistribution is given. The outcome is summarised in column three of Table 4, which reports the percentage reduction in poverty as the result of the redistribution. For example, pre-redistribution poverty in Brazil was measured as 23.2 percent of the population, and is simulated to be 18.4 percent after redistribution, for a fall of 20.7 percent (4.8 percentage points). The final column of the table gives the implicit tax rates on the highest quintile resulting from the redistribution. These prove to be quite low, varying from less than two percent to a high of three percent, inversely related to inequality (ie., the share of income accruing to the top quintile before redistribution).

The poverty reductions associated with redistribution of current income vary dramatically across countries. In general, the lower the per capita income of a country, the less is the poverty reduction. This is demonstrated clearly for the twelve Latin American countries, among which the reduction for the Central American states and Ecuador is virtually nil. The other obvious influence is inequality. Holding per capita income constant, the lower inequality just below the poverty line, the greater the poverty reduction from a redistribution. Comparing the middle-income Latin American countries to the former centrally planned countries reveals this.

These results suggest a typology of countries based on the general strategy that is most conducive to poverty reduction, shown in Table 5. Columns two and three give the number of years required for distribution neutral growth and equal distribution growth to achieve the same poverty reduction as a transfer of one percent of national income from the highest to the lowest quintile. To take the first country, Venezuela, distribution neutral growth would require over thirty-four years to reduce poverty by the same amount as the one percentage point redistribution, and equal distribution growth would

\footnotetext{
${ }^{25}$ At the poverty boundary, this redistribution shifts some households above the ones with slightly higher pre-redistribution incomes, but this does not affect the conclusions reached in the text.
} 
require six years. On the basis of these calculations, the fifty countries fall into three categories. In category 1 , the 'income redistribution countries', both growth strategies require more than one year to reduce poverty as much as a straight redistribution. The countries are listed in descending order of the number of years required for distributionneutral growth to match the impact of the one percent redistribution on poverty. For thirty-four of the fifty countries (sixty-eight percent), straight redistribution is the most effective method of poverty reduction.

In category 2 are thirteen 'redistribution with growth' countries, for which redistribution is not the most effective poverty reduction strategy, and equal distribution growth is more effective than distribution-neutral growth. This is emphasised by inclusion of the 'effectiveness ratio' in the final column (taken from Table 3). These countries are characterised either by low per capita income or relatively equal distribution (or some combination of the two). Finally, there is category 3, three 'trickle down' countries, for which growth as such is the most effective vehicle for poverty reduction. The defining characteristic of the trickle down countries is that they have more than fifty percent of their population in poverty as a result of their low per capita income. However, it does not follow that all low income countries would fall into this category. If low income is combined with a relatively equal distribution, as for Niger, equal distribution growth may be more effective in reducing poverty, if only marginally so in that specific case.

The calculations demonstrate that for the majority of middle-income countries, poverty reduction is most effectively achieved by a redistribution of current income. For the same countries, redistribution with growth would be the second-best option, and distribution neutral, or status quo growth, a poor third. Figure 3 demonstrates the relationship between the three poverty strategies and levels of per capita income, for a given level of overall inequality. The graph is constructed using a regression algorithm and the fifty countries in our tables. For each country, the number of years required for distribution neutral growth or redistribution with growth to achieve the same poverty reduction as redistribution of current income is estimated as function of per capita income and the Gini coefficient. The regression equations are only a rough approximation, since the Gini is a crude proxy for the slope of the distribution function just below the poverty 
line (implied by the parameter $\alpha$ in our model) ${ }^{26}$ Using the regressions, two curves are shown, for DNG and RWG, respectively, for a Gini of 40 (close to the average value across the fifty countries). DNG and RWG are judged as less effective than redistribution of current income if they require more than one year to achieve the same percentage point reduction in poverty.

The graph indicates that redistribution with growth becomes more effective when per capita income falls below about US\$ 700, and distribution neutral growth replaces it as most effective when per capita income drops below about US\$ 450 . While the curves are only indicative (inequality varies across countries), they demonstrate the following general points: 1) for middle-income countries redistribution of current income is the most effective method of poverty reduction; 2) for very low income countries, distribution neutral growth is most effective, and 3) the per capita income range for which redistribution with growth is most effective is quite narrow, though it is more effective than DNG except at very low per capita incomes.

In principle, the analogue used to generate Figure 3 could be employed to divide all countries as we have done for the fifty in Table 5. However, this cannot be done with precision in practice, due to lack of distributional data and the problem of consistently measuring per capita income across countries and over time. A very rough estimate of the number of countries in the three categories is possible. If we assume that the Gini coefficients for the countries not in Table 5 lie between 40 and 50, the relevant 'borderline' countries are Senegal (lowest among the redistribution of current income countries) and Niger (lowest among the redistribution with growth countries). We order all developing countries by per capita income using the latest World Bank World Development Indicators (data for 1999), and treat these two countries as the appropriate

\footnotetext{
${ }^{26}$ The regression algorithms are as follows, where $\mathrm{A}(\mathrm{DNG})$ and $\mathrm{A}(\mathrm{EDG})$ are the number of years to achieve the equivalent of a redistribution of current income, PCY is per capita income, and $\mathrm{G}$ is the Gini coefficient. The significance of coefficients is given in parenthesis below the coefficients, and relevant other statistics below them.
}

$$
\begin{aligned}
& \mathrm{A}(\mathrm{DNG})=-79.08+10.77 \ln (\mathrm{PCY})+3.55 \ln (\mathrm{G}) \\
& \mathrm{R} 2=. .01) \quad(.01) \quad \mathrm{F}=19.8 \quad \mathrm{~N}=47 \\
& \mathrm{~A}(\mathrm{EDG})=-6.38+2.91 \ln (\mathrm{PCY})-2.94 \ln (\mathrm{G}) \\
&(\mathrm{nsgn}) \quad(.01)
\end{aligned}
$$


boundaries for the three categories of poverty reduction strategies. Using this rough method, of 132 developing countries the count is the following: redistribution of current income would be most effective for sixty-five; redistribution with growth for twenty; and distribution neutral growth for the remaining forty-seven. If a political judgement rejected redistribution of current income, then two-thirds of the countries should, on technical grounds, pursue a poverty reduction strategy that purposefully seeks to alter the distribution of the increment in growth. These eighty or more countries include all the middle-income countries, almost all the European and Asian countries in transition, and many of the low-income countries. On the other hand, for almost all countries in the United Nations category of Least Developed Countries a distribution neutral growth path would be the most poverty reducing. With these generalisations in mind, we consider poverty reduction policies in the following section.

Adjusted $\mathrm{R}^{2}=.49 \quad \mathrm{~F}=20.1 \quad \mathrm{~N}=47$ 


\section{Policy Effectiveness for Redistribution with Growth}

The major element required to introduce and effectively implement a redistributive strategy in any country is the construction of a broad political coalition for poverty reduction (see Bell 1974). The task of this coalition would be the formidable one of pressuring governments for redistribution policies, while neutralising opposition to those policies from groups whose self-interest rests with the status quo. How such a political coalition might come about is specific to each country and its discussion beyond the scope of this paper. We focus on a less fundamental, but crucially practical issue: the policies that could bring about a redistribution strategy. To be policy relevant, our consideration of redistribution mechanisms must move beyond a listing of possibilities to an analysis of the likely effectiveness of these.

First, the question of effectiveness should be considered on the macro level, by returning to the question raised in the first section: what are the opportunity costs of reducing poverty by increasing the growth rate and implementing redistribution? The opportunity cost of implementation will be determined by the specifics of the programme to achieve redistribution, the size of the redistribution, and the administrative capacity of the public sector. None of these can be determined in the abstract. However, the opportunity cost of raising the growth rate can be quantified within broad limits. From equation six, we have:

$$
n=-y[1 / \alpha][\mathrm{P} / \beta]^{(1 / \alpha)}
$$

The consumption foregone to achieve any growth rate $\mathrm{y}$ is determined by the familiar equation, $y=s v$, where $s$ is the net saving rate and $v$ is the output-capital ratio. The opportunity cost of lowering poverty through growth alone can be indicated using the calculations for the Latin American countries. Table 3 shows that a distribution neutral growth rate of one percent reduces poverty by .32 percentage points, while equal distribution growth would achieve the same reduction with a growth rate of 26 percentage points. To double the distribution neutral growth reduction of poverty would require an increase of the saving rate of the amount $(1 / \mathrm{v})$. If the capital-output ratio is approximately four, then increasing the annual rate of poverty reduction by one 
percentage point calls for an increase in the saving rate of four percentage points. Equal distribution growth would achieve the same poverty reduction with one percentage point increase in the saving rate. The difference in the required changes in the saving rate implies that equal distribution growth would have a substantially lower opportunity cost of poverty reduction (three percentage points of GDP).

Therefore, equal distribution growth would be a more economically efficient way to reduce poverty as long as its administrative cost did not exceed three percentage points of GDP. To continue with the example for the Latin American region, equal distribution growth of one percent for one period would redistribute half of one percent of national income. If this small redistribution could be achieved with an administrative outlay of less than three percentage points of national income, then EDG would be more effective than DNG.

The opportunity cost of the two growth patterns is demonstrated in Figure 4. The increase in the saving rate required to raise the growth rate one percentage point is equal to the capital-output ratio. As an approximation, it is assumed that the capita-output ratio is an increasing function of per capita income. We assume that the ratio is three for the poorest country of the fifty (Zambia), and 4.5 for the country with the richest (Thailand), and increases linearly with per capita income. This, shown by the straight line DNG, is compared to an increase in the saving ratio for the equal distribution growth rate that generates the same percentage point poverty reduction. For all but nine countries (noted in the chart), the 'savings gap' between DNG and EDG increases with per capita income. Seven of these were countries in transition from central planning, with low initial poverty and/or low inequality. To summarise: 1) the opportunity cost of lowering poverty through growth alone rises with per capita income; and 2) the likelihood that the administrative costs of redistribution would render EDG as or more expensive than DNG decreases with per capita income. Arguments that assert that redistribution to be 'too expensive' appear unfounded when one that considers the opportunity cost of reducing poverty through growth alone. ${ }^{27}$

\footnotetext{
${ }^{27}$ For any particular programme, administrative costs would have to be carefully calculated and compared to those of alternative policies. There is relatively little work on this topic. For a case study, see Grosh (1995).
} 
Turning to specific measures for redistribution, perhaps the most important determinant of the effectiveness of the various measures of each redistribution strategy is the structure of an economy. This structure depends on the level of development, which will to a great extent condition the country's production mix, the endowments of socioeconomic groups, the remuneration to factors, direct and indirect taxes on income and assets, prices paid for goods and services, and transfer payments. These elements of the distribution system are initial conditions that delineate the scope for redistributive policies. The implementation requirements of redistributive policies can be summarised in a simple algebraic framework (see Hanmer et.al. 1997). Define the following terms:

$\mathrm{Y}$ denotes the income of a household, $\mathrm{V}$ is transfer payments, $\mathrm{T}$ is taxes, $\mathrm{k}$ is a vector of assets (including human capital), w is a vector of rates of return (including wages), $\mathrm{p}$ is the price vector of goods and services, $\mathrm{q}$ is the quantity vector of those goods and services, and $\mathrm{S}$ is household saving.

By definition,

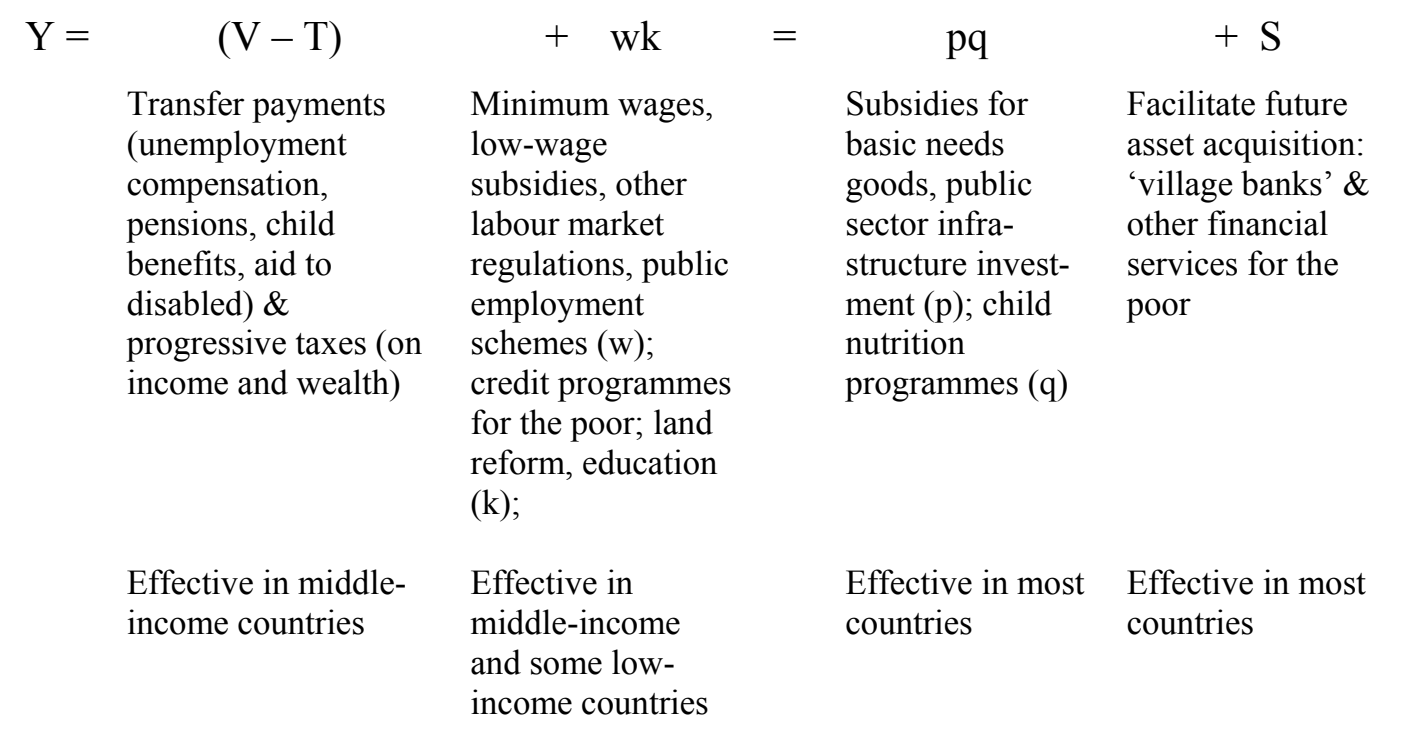

The effectiveness of tax and expenditure policies ( $\mathrm{V}$ and $\mathrm{T}$ ) to generate secondary and tertiary distributions more equitable than the primary distribution depends upon the relative importance of the formal sector. ${ }^{28}$ This is because governments can most effectively apply progressive income taxes to wage employees and corporations. All empirical evidence shows that the formal sector wage bill and profit shares increase with

${ }^{28}$ For a review of fiscal policies for redistribution, see Chu, Davoodi \& Gupta 1999). 
the level of development. Along with the importance of the formal sector goes urbanisation, and working-poor urban households are more easily targeted than either the rural poor or urban informal sector households. The experience of a number of middleincome countries has demonstrated the effectiveness of basic income payments for poverty reduction, with an example being the basic pension paid to the elderly in South Africa. $^{29}$

A redistribution strategy is most appropriate for middle-income countries, because their per capita incomes are high relatively to the absolute poverty line. These are also the countries whose economic structures make taxation and expenditure instruments effective for redistribution. Thus, the thirty-seven 'income redistribution' countries, and others at similar levels of development, qualify for the redistributive strategy via fiscal policy, both in terms of its intrinsic effectiveness and the institutional capacity to implement it. Such countries would include the larger ones in Latin America (Argentina, Brazil, Chile, Mexico and Venezuela), several Asian ones (the Republic of Korea, Thailand, and Malaysia), and virtually all former socialist countries of Central and Eastern Europe.

Specific economic structures can allow for effective use of taxation for redistribution in a few low-income countries that would typically be relevant only for middle-income countries. If the economy of a low-income country is dominated by petroleum or mineral production, then modern sector corporations may generate a large portion of national income. This allows for effective taxation even though administrative capacity of the public sector may be limited. The tax revenue can be redistributed through poverty-reduction programmes, though not through transfer payments if the labour force is predominantly rural. Examples of mineral-rich low-income countries with the potential to have done this, albeit unrealised, were Nigeria and Zambia.

Interventions to change the distribution of earned income (wk in the equation above), which alter market outcomes, will also tend to be more effective in middleincome countries (ILO 1992). The most common intervention is a minimum wage, though there are many other policies to improve earnings from work (see Rogers 1995).

\footnotetext{
${ }^{29}$ While relatively low, the pension in the 1990s was an important income source for the both urban and rural poor, especially for female-headed households (see Standing, Sender and Weeks
} 
Further mechanisms include public employment schemes and tax subsidies to enterprises to hire low-wage labour. It is unlikely that any of these would be effective in low-income countries, because of enforcement problems (minimum wage), targeting difficulties (employment schemes), and narrowness of impact (wage subsidies).

Land reform might achieve poverty reduction for rural households, but the relationship between land redistribution and level of development is a complex one. On the one hand, low-income countries are predominantly rural, so if land ownership is concentrated, its redistribution could have a substantial impact on poverty. The more underdeveloped a country, the less commercialised tend to be poor rural households. Therefore, the benefits to the poor from land redistribution in low-income countries are less likely to be contingent on support services. On the other hand, lack of administrative capacity and so-called traditional tenure systems represent substantial constraints to land redistribution, especially in the sub-Saharan countries. The usual approach to land redistribution presupposes that it is legally clear from whom the land will be taken and to whom it will be given. There are few sub-Saharan countries in which private ownership is widespread, making redistribution difficult or impossible without prior clarification of ownership claims (Platteau 1992, 1995). While land redistribution is probably not an effective poverty reducing measure for most low-income countries, a few notable exceptions in Asia (e.g., India and Vietnam) suggest that it should not be ruled out.

Experience in Latin America has shown that governments can effectively implement land redistribution, though subsequent poverty reduction is dependent on provision of rural support services (Thiesenhusen 1989), including agricultural extension and marketing facilities. Perhaps more serious, the relevance of land reform for poverty reduction tends to decline as countries develop and the rural population shrinks. At the end of the twentieth century in the five most populous Latin American countries, twenty percent or less of the labour force was in agriculture. Minimum wages may be more relevant than land redistribution in reducing poverty among the landless and nearlandless in such countries. ${ }^{30}$

1996, Chap 6).

${ }^{30}$ This is particularly the case if there are no output gains from land redistribution; i.e., if the socalled inverse size rule does not hold (see Dyer 1997). 
Interventions that directly affect the prices and access to goods and services (pq) could potentially be quite powerful instruments for poverty reduction. Subsidies to selected commodities have the administrative advantage of not requiring targeting, only identification of those items that carry a large weight in the expenditure of the poor. While multilateral adjustment programmes typically require an end to such subsidies on grounds of allocative efficiency or excessive budgetary cost, the rules of the World Trade Organisation do not, as long as subsidies do not discriminate between domestic production and imports (FAO 1998). Whether subsidies would generate excessive fiscal strain would depend on the products covered and financing. Again, the level of development of a country is of central importance for the effectiveness of subsidies. In low-income countries with the majority of the poor in the countryside, consumer subsidies are unlikely to have a significant impact on the poor outside urban areas. Basic goods provision in kind can be an effective instrument for poverty reduction even in very low-income countries, by delivering such items as milk to school children. To do so with a non-targeted programme would probably require a progressive tax, which would be more likely in a middle-income country.

In all countries the poor suffer from poor health and inadequate education relatively to the non-poor. Expenditures on infrastructure, education and health have the practical advantage that programmes that would help the poor are easily identified, though the specifics would vary by country. Targeting these to the poor may in some countries be as politically difficult as more obviously controversial measures such as asset redistribution.

Table 6 provides a summary of the discussion, with poverty-reducing measures listed by rows, and the three categories of countries across columns. The table indicates that for the 'redistribution' countries, a transfer of current income and assets is the most effective means of poverty reduction, and the methods to achieve this are feasible. For these countries redistribution is not an alternative to growth; rather it is a feasible and effective complement to growth. For the 'redistribution with growth' countries, the measures for transfer of current income and assets are less feasible, but the more modest goal of redistributing the growth increment would be feasible. Finally, most redistribution instruments would not be feasible for very low-income countries. 
An agenda of redistribution involves major problems, but these problems should not be exaggerated. They might prove no more intractable than the problems associated with implementation of other economic policies. An effective orthodox monetary policy is difficult to implement if a country is too small or underdeveloped to have a bond market (e.g. inability to 'sterilise' foreign exchange flows). Similarly, replacing tariffs by a value added tax would be a daunting task in a country whose commerce was primarily through small traders. Lack of public sector capacity would limit the ability to execute a range of so-called supply side policies: privatisation, 'transparency' mechanisms', and decentralisation of central government service delivery (van der Hoeven and van der Geest 1999). The multilateral agencies have recognised these constraints to adjustment programmes, and typically made the decision that constrained implemented was preferable to non-implementation. The same argument can be made for a redistributive growth strategy: to achieve poverty reduction, it might preferable to implement redistributive growth imperfectly than to implement the status quo imperfectly.

\section{Conclusion}

Poverty reduction has been a priority of development policy, albeit sometimes only at the rhetorical level. The end of the 1990s brought increased emphasis on bringing the benefits of growth to the poor (Rodrik 1994, Alesina 1998, Bruno, Ravallion \& Squire 1998). However, growth alone is a rather blunt instrument for poverty reduction, since the consensus of empirical work suggests that typically it is distribution neutral. Along with emphasis on poverty reduction, a shift occurred in the literature towards a more favourable view of policies to redistribution income and assets. An integration of distributional concerns and priority on poverty reduction could be the basis for a new policy agenda to foster both growth and equity.

This new agenda would be based on three analytical generalisations: 1) that greater distributional equality provides a favourable 'initial condition' for rapid and sustainable growth; 2) that redistribution of current income and assets, or redistribution of an economy's growth increment is the most effective form of poverty reduction for 
most countries; 3) the mechanisms to achieve the redistributions are feasible for most countries; and 4) the administrative costs of these mechanisms are highly unlikely to cancel out the gains in poverty reduction. These generalisations imply that the new agenda could focus upon specific policies and instruments of redistribution, with the goal of substantial reductions in urban and rural poverty in the medium term. To reduce poverty, growth is not enough, nor is redistribution enough. Required is a growth policy that incorporates equity as a fore-thought, rather than an after-thought, by shifting the ideological debate so that the costs and limits of growth are viewed as sceptically as the costs and limits of redistribution. 


\section{REFERENCES}

Ahluwalia, M. S.

1974a "Income Inequality: Some Dimensions of the Problem" in Redistribution with Growth by H. Chenery, M. S. Ahluwalia, C. L. G. Bell, J. H. Duloy and R. Jolly, (Oxford: Oxford University Press) pp. 3-37

1974b "The Scope For Policy Intervention", in Redistribution with Growth by H. Chenery, M. S. Ahluwalia, C. L. G. Bell, J. H. Duloy and R. Jolly, Chapter IV, (Oxford: Oxford University Press) pp. 73-90

Aghion, P.; Caroli, E.; Garcia-Penalosa, C.

1999 "Inequality and Economic Growth: The Perspective of the New Growth Theories", Journal of Economic Literature, Vol. XXXVII, December, pp. 16151660

Ahluwalia, M. S.; Chenery, H.

1974a "The Economic Framework", in Redistribution with Growth by H. Chenery, M. S. Ahluwalia, C. L. G. Bell, J. H. Duloy and R. Jolly, Chapter II, (Oxford: Oxford University Press) pp. 38-51

1974b "A Model of Redistribution and Growth", in Redistribution with Growth by H. Chenery, M. S. Ahluwalia, C. L. G. Bell, J. H. Duloy and R. Jolly, (Oxford: Oxford University Press) pp. 209-235

Alesina, A.

1998 "The Political Economy of Macroeconomic Stabilizations and Income Inequality: Myths and Reality" in Income Distribution and High-Quality Growth, V. Tanzi and K. Chu (eds.), (Cambridge, Mass: MIT Press) pp. 299-326.

Alesina, A.; Rodrik, D.

1994 "Distributive Politics and Economic Growth", Quarterly Journal of Economics, Vol. 109, No.2, pp. 465-490

Rodrik, D.

1994 "Distributive Politics and Economic Growth", Quarterly Journal of Economics, Vol. 109, No.2, pp. 465-490

Bell, C. L. G.

1974 "The Political Framework" in Redistribution with Growth by H. Chenery, M. S. Ahluwalia, C. L. G. Bell, J. H. Duloy and R. Jolly, Chapter V, (Oxford: Oxford University Press)

Brundenius, Claes, and Weeks, John

2001 "Globalization and Third World Socialism," in Claes Brundenius and John Weeks (eds.), Globalization and Third World Socialism: Cuba and Vietnam (London: Palgrave)

Chenery, H., M. S. Ahluwalia, C. L. G. Bell, J. H. Duloy and R. Jolly (Chenery, et. al.) 1974 Redistribution with Growth (Oxford: Oxford University Press)

Chu, K.; Davoodi, H.; Gupta, S

1999 "Income Distribution and Tax and Government Spending Policies in Developing Countries", Draft Paper Prepared for WIDER Project Meeting on Rising Income Inequality and Poverty Reduction, 16-18 July 1999, Helsinki

Cornia, G. A. 
1999 "Liberalization, Globalization and Income Distribution", WIDER Working Paper Series, No. 157, March 1999

Cornia, G. A.; Reddy, S.

1999 "The Impact of Adjustment Related Social Funds on Distribution and Poverty", WIDER Project Meeting on Rising Income Inequality and Poverty Reduction, 16-18 July 1999, Helsinki

Cramer, Chris

2000 "Inequality, Development and Economic Correctness," SOAS Department of Economics Working Papers, No.105, (London: School of Oriental and African Studies)

Dagdeviren, H., John Weeks and Rolph van der Hoeven 2000 'Redistribution Matters: Growth for Poverty Reduction', SOAS Department of Economics Working Papers, No. 99, (London: School of Oriental and African Studies)

Deininger, K., and L. Squire

1996 'A New Data Set Measuring Income Inequality,' World Bank Economic Review 10, pp. 565-592

Demery, L., and M. Walton

1998 'Are Poverty and Social Goal for the 21st Century Attainable?' IDS Bulletin, 30

Department for International Development (UK)

1997 Eliminating World Poverty: A challenge for the 21 ${ }^{\text {st }}$ Century (London: The Stationery Office)

2000 Halving world poverty by 2015: Economic growth, equity and security (London: DFID)

Dollar, David, and Aart Kray

2000 'Growth is Good for the Poor,' (www.worldbank.org/research: World Bank)

Dyer, Graham

1997 Class, State and Agricultural Productivity in Egypt. A Study of the Inverse Relationship between Farm Size and Land Productivity, (London: Frank Cass)

Fields, Gary

1980 Poverty, Inequality and Development (Cambridge: Cambridge University Press)

Ferreira, Francisco H. G.

1999 'Inequality and Economic Performance,' (www. worldbank.org/poverty/ inequal/index.htm: World Bank)

Food and Agricultural Organisation, Statistics Division

1998 The implications of the Uruguay Round Agreement on Agriculture for Developing Countries, Training Materials for Agricultural Planning 41 (Rome: FAO)

Goudie, Andrew, and Paul Ladd

1999 'Economic Growth, Poverty and Inequality,' Journal of International Development, 11, 2, pp. 177-195

Grosh, M. E. 
1995 "Towards Quantifying the Trade-off: Administrative Costs and Incidence in Targeted Programs in Latin America", in Public Spending and the Poor, , D. van de Walle and K. Neat (eds.), (Baltimore: John Hopkins University Press for the World Bank) pp. 450-88.

Hanmer, L., and F. Nascold 2000 'Attaining the International Development Targets: Will growth be enough?' Development Policy Review 18, 1, pp. 11-36

International Fund for Agricultural Development (IFAD) 1999 "Rural Poverty: A Regional Assessment", IFAD, Latin America and Caribbean Division, September

International Labour Organisation (ILO)

1992 Incomes Policies in the Wider Context: Wage, Price and Fiscal Initiatives in Developing Countries, F. Paukert and D. Robinson (eds.), 1992, (Geneva: International Labour Office)

IMF and The World Bank

1999 Poverty Reduction Strategy Papers: Operational Issues, (Washington:

Kanbur, R. World Bank)

1998 "Income Distribution and Growth", World Bank Working Papers: 98-13, (Washington: The World Bank)

Kanbur, R.; Squire, L.

1999 "The Evolution of Thinking about Poverty: Exploring the Interactions" mimeographed document, World Development Report Office , (Washington: World Bank)

Karshenas, Massoud 2001 "Measurement of Absolute Poverty in Least Developed Countries (LDCs)," SOAS Department of Economics Working Paper (London: School of Oriental and African Studies)

Lubker, Malte, Graham Smith and John Weeks

2002 'Growth and the Poor: A comment on Dollar and Kraay,' SOAS Department of Economics Working Paper, (London: School of Oriental and African Studies)

Milanovic, B.

1999 "Explaining the Increase in Inequality During the Transition", The World

Bank Policy Research Department Paper, Washington D.C.: The World Bank

Platteau, Jean-Philippe

1992 "Land Reform and Structural Adjustment in sub-Saharan Africa: controversies and guidelines," FAO Economic and Social Development Paper 107 (Rome: FAO)

1995 Reforming Land Rights in Sub-Saharan Africa: Issues of Efficiency and Equity, Research Institute for Social Development, Discussion Paper 60

Psacharopoulis, George, Samuel Morley, Ariel Fiszbein, and Bill Wood 1996 Poverty and Income Distribution in Latin America: The story of the 1980s, World Bank Technical Paper No. 351 (Washington: World Bank)

Ravallion, $\mathrm{M}$. 
2001 'Growth, Inequality and Poverty: Looking beyond averages,' UNU/WIDER Development Conference on Growth and Poverty, Helsinki, 25-26 May

Standing, Guy, Sender, John and Weeks, John

1996 Restructuring the Labour Market: The South African Challenge (Geneva: ILO)

Thiesenhusen, W. H.

1989 Searching for Agrarian Reform in Latin America (Winchester, MA: Unwin Hyman)

van der Hoeven, R.

2000 "Poverty and Structural Adjustment. Some Remarks on the Trade-off between Equity and Growth," in New Poverty Strategies, What have they achieved, What have we learned? P. Mosley and A. Booth (eds.) (London Macmillan).

van der Hoeven, R. and van der Geest, W.

1999 "Africa's Adjusted Labour Markets. Can Institutions Perform?" In: Adjustment, Employment and Missing Institutions in Africa W. van der Geest and R. van der Hoeven (London: James Currey)

United States Agency for International Development 2001 USAID Strategies for Sustainable Development: Encouraging Broad-based Economic Growth (www.usaid.gov/economic growth/strategy.htm)

World Bank

1993 The East Asian Miracle (Oxford: Oxford University Press)

2000 Global Economic Prospects and the Developing Countries 2000 (Washington: World Bank)

2001a Global Economic Prospects and the Developing Countries 2001 (Washington: World Bank)

2001b The International Development Goals: Strengthening Commitments and Measuring Progress, background note prepared by the World Bank Group for the Westminster Conference on Child Poverty, London, 26 February 
Figure 1:

Relationship between Inequality and Per Capita Income for Constant Levels of Headcount Poverty

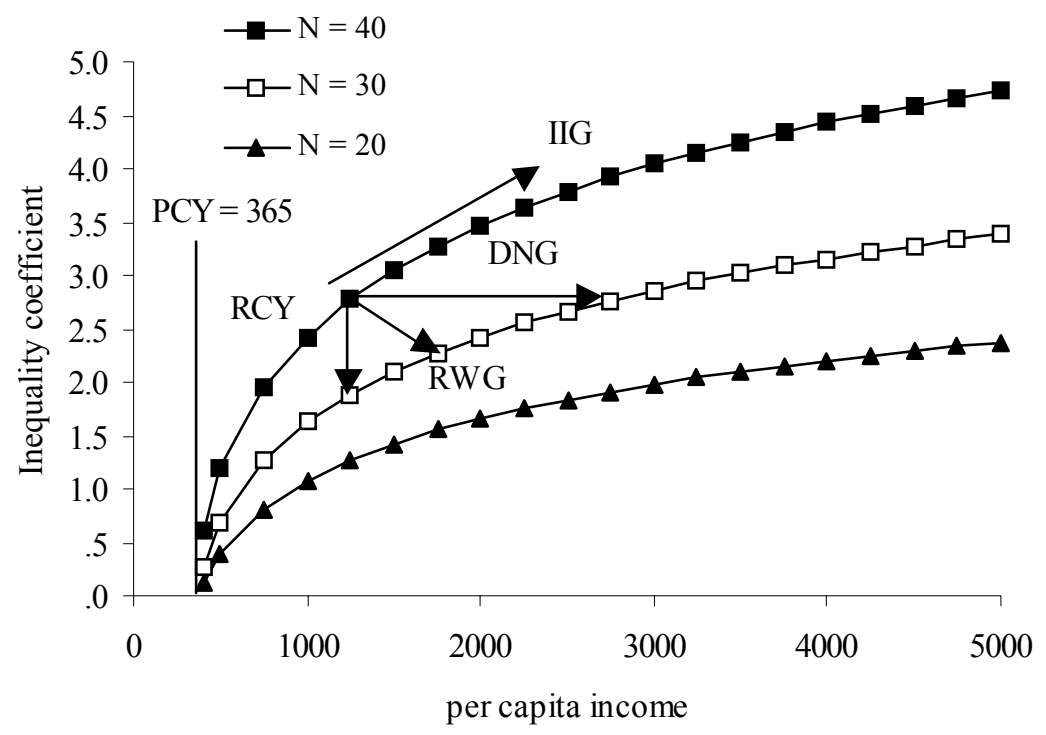

Figure 2:

Poverty Reduction and GDP Growth for Degrees of Inequality

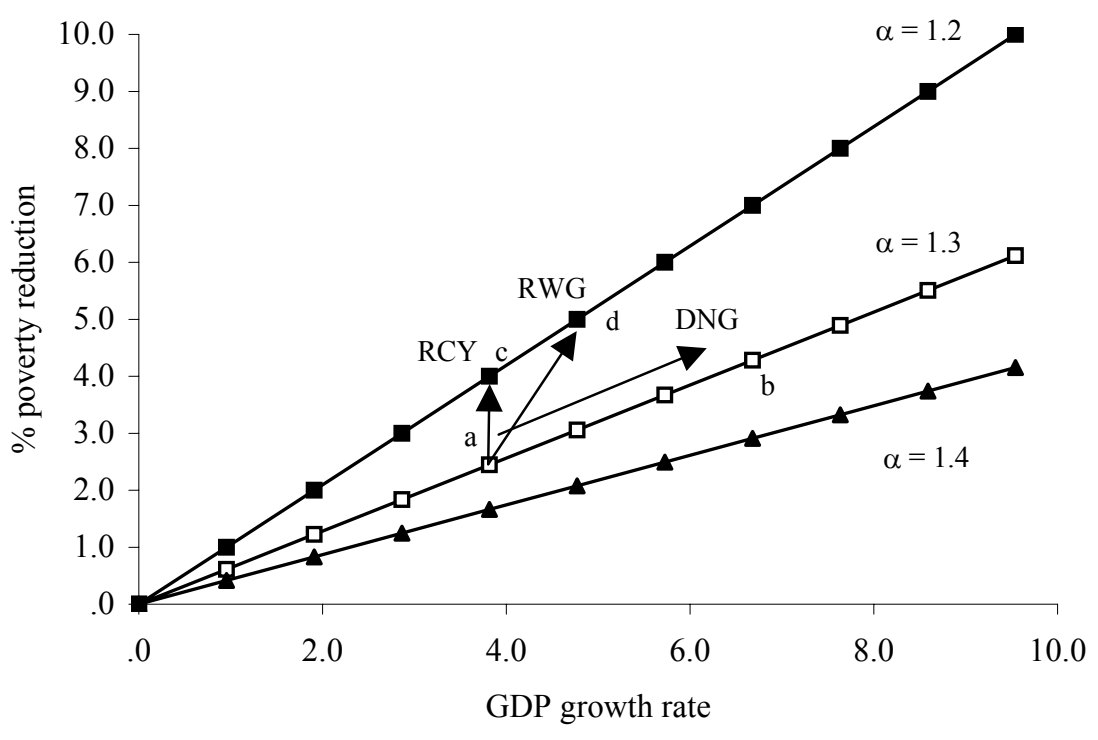


Figure 3

Effectiveness of Poverty Reduction Strategies, NDG \& RWG, for Given Levels of Inequality (from cross-country regression)

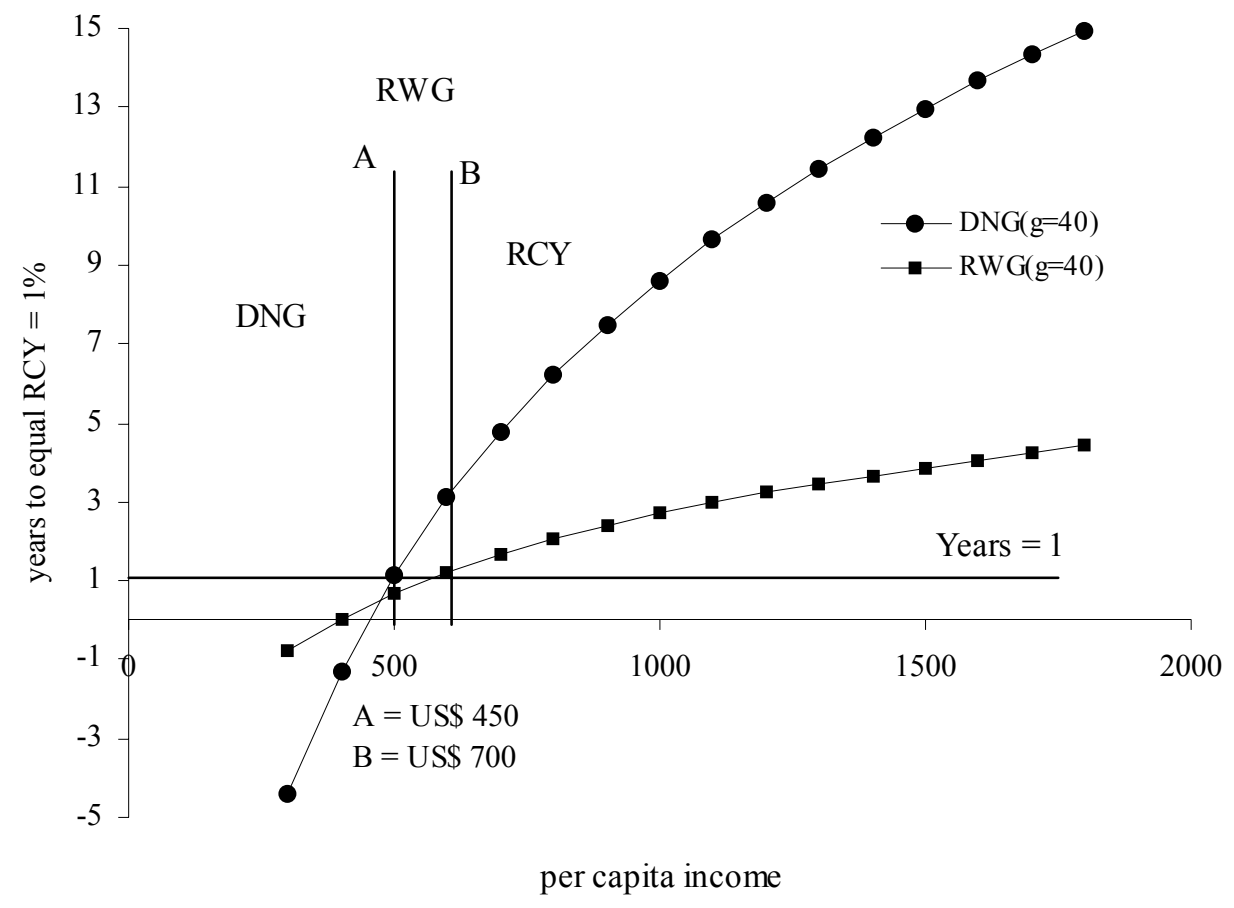

Figure 4 
Table 1: Growth Rates Required to halve poverty by 2015 and Income Shares

\begin{tabular}{|l|c|c|c|c|c|c|}
\hline Region & \multicolumn{2}{|c|}{$\begin{array}{c}\text { Per capita growth } \\
\text { rates: }\end{array}$} & \multicolumn{2}{|c|}{ Target } & \\
\hline Item: & $\begin{array}{c}\text { To meet } \\
\text { target } \\
2000-15\end{array}$ & $\begin{array}{c}\text { Actual } \\
1965-97\end{array}$ & $\begin{array}{c}\text { Actual } \\
1990-97\end{array}$ & $\begin{array}{c}\text { Actual } \\
1965-97\end{array}$ & $\begin{array}{c}\text { Actual } \\
1990-97\end{array}$ & $\begin{array}{c}\text { Income } \\
\text { share, top } \\
20 \%\end{array}$ \\
\hline Sub-Sahara & 5.9 & -0.2 & -0.7 & 6.1 & 6.6 & 52 \\
\hline ME \& NA & 2.8 & 0.1 & 0.7 & 2.7 & 2.1 & na \\
\hline EAP & 3.5 & 5.4 & 7.7 & -1.9 & -2.2 & 44 \\
\hline South Asia & 3.9 & 2.3 & 3.3 & 1.6 & 0.6 & 40 \\
\hline LAC & 7.0 & 1.3 & 2.1 & 5.7 & 4.9 & 53 \\
\hline EE\&CA & 3.8 & 3.2 & -4.1 & 0.6 & 7.9 & na \\
\hline
\end{tabular}

Notes:

ME\&NA - Middle East and North Africa

EAP - East and the Pacific

LAC - Latin America \& the Caribbean

EE\&CA - Eastern Europe and Central Asia

*A negative number indicates that the region grew faster than the rate necessary to meet the poverty target.

Sources: Growth rates, Hanmer \& Nascold (2000); income share, Deininger \& Squire (1996), for the 1990s; and DFID (2000, pp. $16 \& 22$ ), where the numbers are reproduced. Similar calculations can be found in World Bank (2000) and World Bank (2001a).

\section{Tables 2-5 in excel file.}

Table 6: Summary of Feasibility of Redistribution Instruments by Category of Country

\begin{tabular}{|c|c|c|c|}
\hline $\begin{array}{l}\text { Country } \\
\text { Category: } \\
\text { Redistributive } \\
\text { Instrument: }\end{array}$ & $\begin{array}{c}\text { Redistribution of } \\
\text { current income \& assets } \\
\text { (middle-income } \\
\text { countries) }\end{array}$ & $\begin{array}{l}\text { Growth with } \\
\text { redistribution policies } \\
\text { (middle \& most low- } \\
\text { income countries) }\end{array}$ & $\begin{array}{l}\text { Growth without } \\
\text { redistribution policies } \\
\text { (very low-income } \\
\text { countries) }\end{array}$ \\
\hline $\begin{array}{l}\text { Progressive } \\
\text { taxation }\end{array}$ & Yes & $\begin{array}{c}\text { Yes for } \\
\text { some countries }\end{array}$ & No \\
\hline $\begin{array}{l}\text { Transfer } \\
\text { payments }\end{array}$ & Yes & $\begin{array}{c}\text { Yes for } \\
\text { some countries }\end{array}$ & No \\
\hline $\begin{array}{l}\text { Consumer } \\
\text { subsidies }\end{array}$ & Yes & Yes & $\begin{array}{c}\text { Yes for } \\
\text { some countries }\end{array}$ \\
\hline $\begin{array}{l}\text { Land } \\
\text { reform }\end{array}$ & $\begin{array}{c}\text { Yes, but not } \\
\text { always relevant }\end{array}$ & Yes & $\begin{array}{c}\text { Not for } \\
\text { most countries }\end{array}$ \\
\hline $\begin{array}{l}\text { Education \& } \\
\text { health }\end{array}$ & Yes & Yes & Yes \\
\hline $\begin{array}{l}\text { Infrastructure } \\
\& \text { public works }\end{array}$ & Yes & Yes & Yes \\
\hline
\end{tabular}

